\title{
18F-FDOPA PET/CT accurately identifies MEN1-associated pheochromocytoma
}

\author{
Aisha A Tepede1, James Welch1, Maya Lee1, Adel Mandl1, Sunita K Agarwal', \\ Naris Nilubol2 ${ }^{\text {, Dhaval Patel2 }}$, Craig Cochran', William F Simonds', Lee S Weinstein', \\ Abhishek Jha ${ }^{4}$, Corina Millo ${ }^{3}$, Karel Pacak ${ }^{4}$ and Jenny E Blau ${ }^{1}$ \\ ${ }^{1}$ Metabolic Diseases Branch, National Institute of Diabetes and Digestive and Kidney Disease (NIDDK), ${ }^{2}$ National \\ Cancer Institute $(\mathrm{NCI})$, ${ }^{3}$ Clinical Center PET Department (CC PET), and ${ }^{4}$ Eunice Kennedy Shriver National Institute of \\ Child Health and Development (NICHD), National Institutes of Health, Bethesda, Maryland, USA
}

\author{
Correspondence \\ should be addressed \\ to J E Blau \\ Email \\ Jenny.blau@nih.gov
}

\section{Summary}

Pheochromocytoma (PHEO) in multiple endocrine neoplasia type 1 (MEN1) is extremely rare. The incidence is reported as less than 2\%. We report a case of a 76-year-old male with familial MEN1 who was found to have unilateral PHEO. Although the patient was normotensive and asymptomatic, routine screening imaging with CT demonstrated bilateral adrenal masses. The left adrenal mass grew from 2.5 to $3.9 \mathrm{~cm}$ over 4 years with attenuation values of 9 Hounsfield units (HU) pre-contrast and $15 \mathrm{HU}$ post-contrast washout. Laboratory evaluation demonstrated an adrenergic biochemical phenotype. Both ${ }^{18} \mathrm{~F}$-fluorodeoxyglucose (18F-FDG) PET/CT and ${ }^{123}$-metaiodobenzylguanidine (123I-mIBG) scintigraphy demonstrated bilateral adrenal uptake. In contrast, ${ }^{18} \mathrm{~F}$-fluorodihydroxyphenylalanine (18F-FDOPA) PET/CT demonstrated unilateral left adrenal uptake (28.7 standardized uptake value (SUV)) and physiologic right adrenal uptake. The patient underwent an uneventful left adrenalectomy with pathology consistent for PHEO. Post-operatively, he had biochemical normalization. A review of the literature suggests that adrenal tumors $>2 \mathrm{~cm}$ may be at higher risk for pheochromocytoma in patients with MEN1. Despite a lack of symptoms related to catecholamine excess, enlarging adrenal nodules should be biochemically screened for PHEO. 18F-FDOPA PET/CT may be beneficial for localization in these patients.

\section{Learning points:}

- 18F-FDOPA PET/CT is a beneficial imaging modality for identifying pheochromocytoma in MEN1 patients.

- Adrenal adenomas should undergo routine biochemical workup for PHEO in MEN1 and can have serious perioperative complications if not recognized, given that MEN1 patients undergo frequent surgical interventions.

- MEN1 is implicated in the tumorigenesis of PHEO in this patient.

\section{Background}

Multiple endocrine neoplasia type 1 (MEN1) is a rare autosomal dominant syndrome with a prevalence estimated around 2-3/100 000. Clinical manifestations include anterior pituitary adenomas, primary hyperparathyroidism, and duodenal/pancreatic neuroendocrine tumors (1). While the prevalence of adrenal tumors in MEN1 has been estimated to be as high as $45 \%$, they are typically bilateral, non-functional cortical adenomas (2). Pheochromocytoma
(PHEO) in MEN1 is a rare occurrence, estimated to occur in $<2 \%$ of patients with MEN1 (3).

Once a biochemical diagnosis of $\mathrm{PHEO} /$ paraganglioma is established, anatomical and functional imaging is helpful to determine or confirm the location of PHEO or extra-adrenal paraganglioma, evaluate for multiplicity and determine if there is metastasis (4). Additionally, patients who present with bilateral adrenal nodules on anatomic 
imaging may present diagnostic challenges. In patients with a known predisposition to bilateral PHEO, including those with von Hippel-Lindau (VHL), multiple endocrine neoplasia type 2 (MEN2), neurofibromatosis type 1 (NF1) and myc-associated factor X (MAX) gene mutations, the utility of $18 \mathrm{~F}-\mathrm{FDOPA}$ PET/CT for identifying PHEOs has been previously demonstrated $(4,5,6,7)$. Here, we report a case of clinically silent PHEO in a patient diagnosed with MEN1 at an advanced age who presented with bilateral adrenal masses and highlight the diagnostic utility of ${ }^{18}$ F-FDOPA PET/CT over ${ }^{123}$ I-MIBG and 18F-FDG PET/CT scanning. We also present a review of the literature of MEN1 patients with PHEO.

\section{Case presentation}

A 70-year-old Caucasian gentleman presented for a workup for MEN1 at our institution because his son had been recently diagnosed with MEN1. Written informed consent to a long-standing natural history hyperparathyroidism protocol (NCT00001277) was obtained prior to study enrollment. At the time of initial presentation, the patient was asymptomatic. Clinical features of PHEO, including sustained or paroxysmal hypertension, sweating, pallor, palpitations, constipation, headaches or weight loss, were notably absent. He had documented normocalcemia until age 60 when he was identified to have hypercalcemia on routine screening and subsequently underwent a single gland parathyroidectomy. A second parathyroidectomy was performed 5 years later due to recurrent hyperparathyroidism. Other pertinent past medical history includes gastrointestinal reflux disease, ischemic stroke, prostate cancer, melanoma, squamous cell skin cancer and type 2 diabetes mellitus. Social history was unremarkable. The patient had a 20 pack/year tobacco history but quit smoking cigarettes at the age of 55. In a review of the family history, it is unknown if either parent had MEN1 (Fig. 1). On physical exam, the patient was normotensive and had a resting heart rate of 94 . Skin exam revealed lipomas on the trunk. Initial screening with computerized tomography (CT) scan demonstrated two cysts in the uncinate process of the pancreas and qualitatively similar bilateral adrenal nodules measuring $2.5 \mathrm{~cm}$ on the left (9 HU pre-contrast and $15 \mathrm{HU}$ postcontrast contrast washout) and a multinodular right adrenal, with the dominant nodule measuring $2.7 \mathrm{~cm}$ (23 HU pre-contrast- and $25 \mathrm{HU}$ post-contrast). MRI confirmed $2.5 \mathrm{~cm}$ left and right adrenal nodules, and the largest right adrenal nodule measured $2.5 \mathrm{~cm}$. MRI characteristics showed left adrenal hyperintense activity

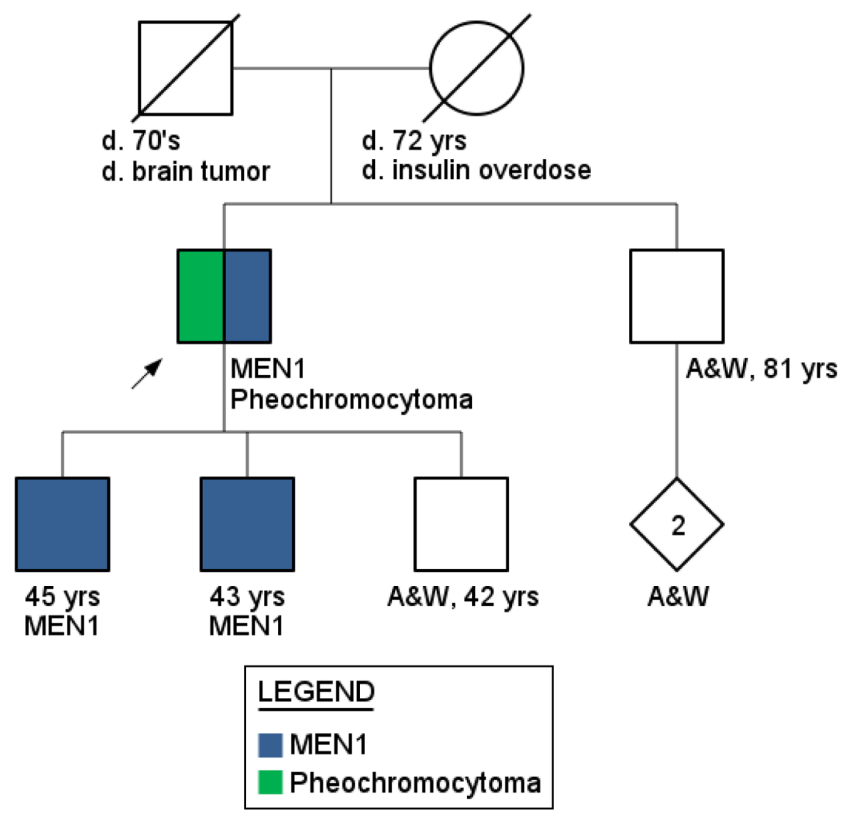

Figure 1

Patient's family tree spanning across three generations. The patient's three sons range from 42 to 45 years of age; arrow indicates the MEN1 index case. A\&W indicates alive and well.

on T2 and hypointense activity on T1, while the right adrenal was isointense on T1. Pituitary MRI was negative.

\section{Investigation}

Initial labs demonstrated slightly elevated ionized Ca (1.38 mmol/L; range: $1.12-1.32 \mathrm{mmol} / \mathrm{L}), \quad \mathrm{PTH}$ (72.3 pg/mL; range: $15-65 \mathrm{pg} / \mathrm{mL}$ ) and low phosphorus ( $2.2 \mathrm{mg} / \mathrm{dL}$; range: $2.5-4.8 \mathrm{mg} / \mathrm{dL}$ ). Gastrin was elevated (302 pg/mL; normal <100 pg/mL), while on $20 \mathrm{mg}$ of omeprazole by mouth daily, and hemoglobin A1c was $7 \%$. Prolactin and all other biochemical tests were within normal limits. Screening evaluation of adrenal function was notable for a seven-fold increase in plasma metanephrine ( $432 \mathrm{pg} / \mathrm{mL}$; range: $12-61 \mathrm{pg} / \mathrm{mL})$, threefold increase in normetanephrine $(291 \mathrm{pg} / \mathrm{mL}$; range: $18-112 \mathrm{pg} / \mathrm{mL}$ ) and two-fold increase in epinephrine (126 pg/mL; range: $0-57 \mathrm{pg} / \mathrm{mL}$ ). Aldosterone was normal ( $<4 \mathrm{ng} / \mathrm{dL}$; normal $<21 \mathrm{ng} / \mathrm{dL}$ ). Chromogranin A was $2443 \mathrm{ng} / \mathrm{mL}$ (normal <93 ng/mL) (Table 1).

Germline mutation testing by the Next Generation Sequencing (NGS) method revealed a heterozygous pathogenic variant MEN1 c.249_252delGTCT causing a frameshift mutation, also known as rs587776841. Germline mutation testing for known pathogenic genes associated with $\mathrm{PHEO} /$ paraganglioma by NGS was negative for RET, NF1 and VHL. In addition, all succinate 
Table 1 Biochemical evaluation of blood and 24-h urine.

\begin{tabular}{|c|c|c|}
\hline Parameters & $\begin{array}{l}\text { Normal } \\
\text { values }\end{array}$ & Patient values \\
\hline \multicolumn{3}{|l|}{ Blood chemistry } \\
\hline $1 \mathrm{mg}$ DST, $\mu \mathrm{g} / \mathrm{dL}$ & $<1.8$ & 2.8 \\
\hline Aldosterone level, ng/dL & $<21$ & $<4$ \\
\hline Metanephrine, pg/mL & $12-61$ & $432(7 \times$ ULN) \\
\hline Normetanephrine, pg/mL & $18-112$ & $291(3 \times$ ULN) \\
\hline Epinephrine, pg/mL & $0-57$ & $126(2 \times$ ULN $)$ \\
\hline Norepinephrine, pg/mL & 84-794 & 198 \\
\hline Chromogranin A, ng/mL & $<93$ & $2443(26 \times$ ULN $)$ \\
\hline Gastrin, pg/mL & $<100$ & $302(3 \times$ ULN) \\
\hline PTH, pg/mL & $15-65$ & 72.3 \\
\hline Ionized Calcium, mmol/L & $1.12-1.32$ & 1.38 \\
\hline \multicolumn{3}{|l|}{ 24-h urine* analysis ( $\mu \mathrm{g} / 24 \mathrm{~h})$} \\
\hline Urine free cortisol & $3.5-45$ & $\begin{array}{l}41.8 ; 61.6 \\
\quad(1-1.5 \text { ULN) }\end{array}$ \\
\hline Urine metanephrine & $44-261$ & $1616(6 \times$ ULN $)$ \\
\hline Urine normetanephrine & $148-560$ & $787(1.5 \times$ ULN $)$ \\
\hline Total metanephrine & $246-753$ & $2403(3 \times$ ULN) \\
\hline
\end{tabular}

*Urine creatinine and volume within normal limits. DST, dexamethasone suppression test.

dehydrogenase subunit mutations were negative by sequencing and deletion analysis, including succinate dehydrogenase complex flavoprotein subunit A (SDHA), succinate dehydrogenase complex assembly factor 2 (SDHAF2), succinate dehydrogenase complex subunit B $(S D H B)$, succinate dehydrogenase complex subunit $\mathrm{C}$ (SDHC), transmembrane protein 127 (TMEM127), MAX, egl-9 family hypoxia inducible factor 1 (EGLN1), fumarate hydratase $(F H)$ and kinesin family member 1B (KIF1B).

During a workup for Zollinger-Ellison Syndrome (ZES), the patient unexpectedly developed a perforated duodenal ulcer requiring prolonged hospitalization and multiple surgeries. Due to these complications, the adrenal nodule was monitored, and over the course of 4 years the right adrenal nodule remained stable while the left increased from $2.5 \mathrm{~cm}$ to $3.9 \mathrm{~cm}$ by CT (Fig. 2A). Functional adrenal imaging with ${ }^{123}$ I-mIBG scintigraphy demonstrated mild abnormal bilateral uptake (Fig. 2B), similar to ${ }^{18}$ F-FDG PET/CT (6.4 SUVmax on the left and 4.4 SUVmax on the right; Fig. 2C). However, ${ }^{18 F-F D O P A ~}$ PET/CT clearly demonstrated an avid uptake in the left adrenal with SUVmax of 28.7 (Fig. 2D), with physiologic uptake on the right adrenal. Gallium-68 $\left({ }^{68} \mathrm{Ga}\right)$ DOTATATE PET/CT was not available at the time.

\section{Treatment}

The patient underwent a successful laparoscopic left adrenalectomy for PHEO (Fig. 2E, F and G) without
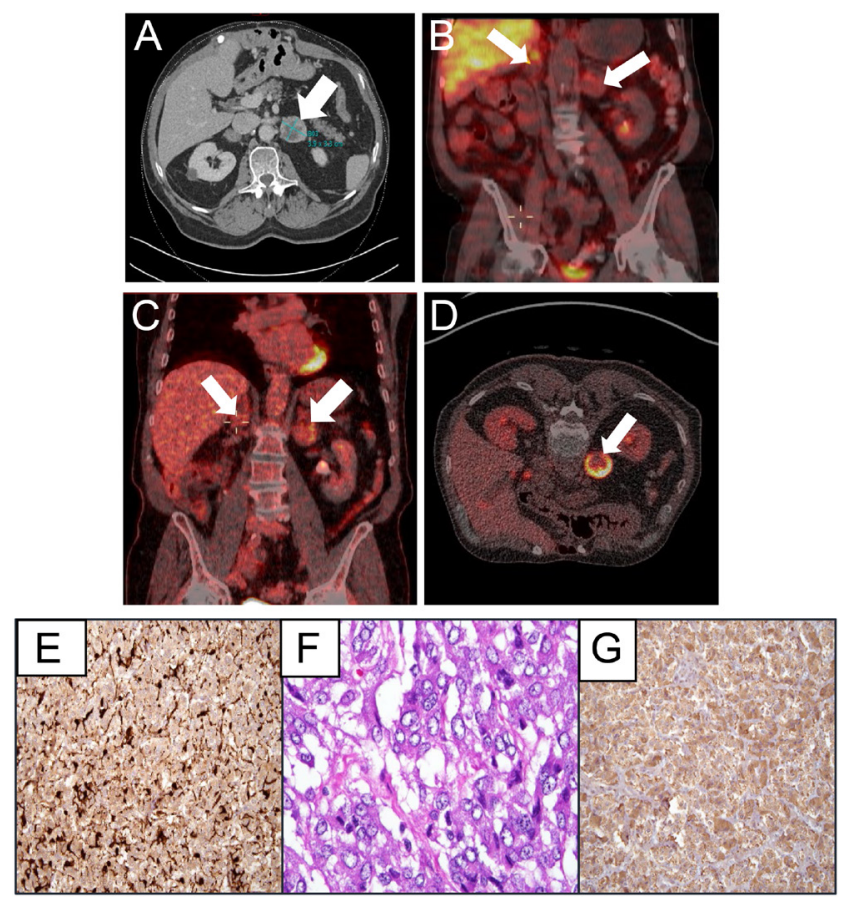

Figure 2

Imaging studies and surgical pathology of the pheochromocytoma. (A) CT demonstrating the left adrenal mass measuring $3.9 \mathrm{~cm}$ (15 Hounsfield unit (HU) post-contrast) and right adrenal mass measuring $2.5 \mathrm{~cm}$. (B) ${ }^{123}$-mIBG demonstrating abnormal uptake corresponding to the right and left adrenal masses. (C) ${ }^{18}$ F-FDG-PET/CT demonstrating bilateral adrenal uptake (6.4 SUVmax on the left and 4.4 SUVmax on the right). (D) ${ }^{18} \mathrm{~F}$-FDOPA PET/CT demonstrating increased uptake in the left adrenal gland (SUVmax 28.7) compared to the right. (E) S100 highlights sustentacular cells, 20×. (F) Hematoxylin and eosin staining, 60×. (G) Chromogranin A staining, 20x.

complications. Pathology revealed positive staining for chromogranin A and S100 highlighted sustentacular cells (Fig. 2E, F and G). Tumor DNA sequencing and analysis of markers near the MEN1 locus demonstrated loss of heterozygosity (LOH), consistent with the Knudson's twohit hypothesis (Fig. 3).

\section{Outcome and follow-up}

Post-operatively, the patient had normalization of previously elevated plasma metanephrines $(27 \mathrm{pg} / \mathrm{mL}$; range $12-61 \mathrm{pg} / \mathrm{mL})$, normetanephrine $(107 \mathrm{pg} / \mathrm{mL}$; range 18-112 pg/mL) and plasma epinephrine $(<20 \mathrm{pg} / \mathrm{mL}$; range $0-57 \mathrm{pg} / \mathrm{mL}$ ). As expected, chromogranin A remains elevated due to the presence of known duodenal and pancreatic neuroendocrine tumors. Additionally, he is normotensive, has no biochemical evidence of recurrence and continues yearly follow-up for MEN1 at our institution for the past 8 years. 


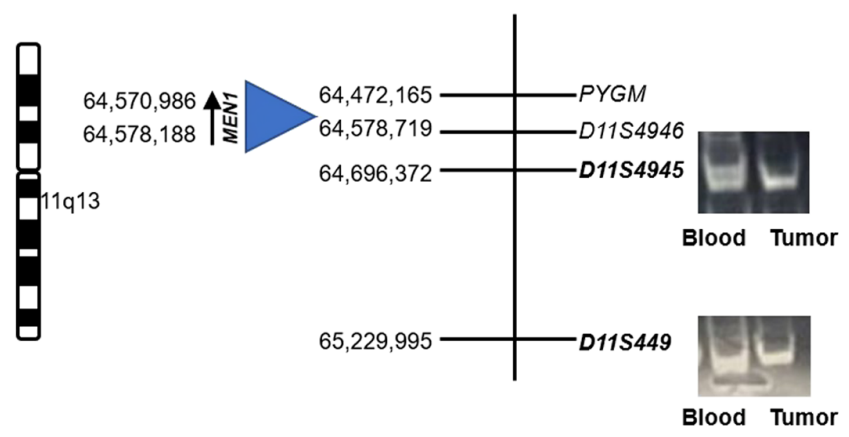

Figure 3

Loss of heterozygosity (LOH) at the MEN1 locus (chromosome 11q13) in the patient's tumor DNA. A diagram indicating the location of chromosome 11q13 markers near the MEN1 gene is shown based on UCSC hg19 in silico PCR with published primers $(27,28)$. LOH was detected at two markers, D11S4945 and D11S449, in the patient's tumor DNA compared to his blood DNA (PCR products resolved in 1× TBE 6\% polyacrylamide gels).

\section{Discussion}

In this report, we describe a patient with a confirmed germline MEN1 mutation and a clinically silent PHEO. Because of the bilateral adrenal masses demonstrated on CT and MRI, ${ }^{123}$ I-mIBG scintigraphy, ${ }^{18} \mathrm{~F}-\mathrm{FDG}$ PET/CT and ${ }^{18} \mathrm{~F}-\mathrm{FDOPA}$ PET/CT were performed to localize the tumor. Only ${ }^{18}$ F-FDOPA PET/CT identified the left PHEO. These results suggest that ${ }^{18} \mathrm{~F}-\mathrm{FDOPA} \mathrm{PET} / \mathrm{CT}$ may be a sensitive tool to capture biochemically-confirmed PHEO, especially in cases with bilateral adrenal hyperplasia/nodules in patients with MEN1.

The incidence of adrenal nodules in patients with MEN1 is reported to be up to $40 \%$ depending on the series, radiological methods and criteria used to characterize adrenal enlargement (2). The majority of these tumors are bilateral, hyperplastic and non-functional. A large multicenter database analysis of patients with MEN1 and adrenal nodules demonstrated increased prevalence of primary hyperaldosteronism and adrenocortical carcinoma compared to sporadic incidentalomas. This cohort series described $4 / 146$ cases of hyperaldosteronism, which were more common in patients with unilateral adrenal lesions. This paper may have overestimated the prevalence of endocrine hypersecretion, as $50 \%$ of asymptomatic patients with adrenal lesions were not biochemically screened and therefore were not included in the prevalence calculation. Only one case of MEN1associated PHEO was identified in this cohort (1/144) (2), and this patient had bilateral PHEOs with obvious clinical features of NF1 (yet no genetic analysis was performed). Similarly, a patient with a germline mutation in MEN1 was reported with clinical findings of both MEN1 and
MEN2, including a PHEO (8). This patient had a negative $R E T$ gene analysis of pathogenic variants but did have germline RET polymorphisms Gly691Ser and Arg982Cys. It remains unclear if either of these variants, individually or in combination, were working in synergy with the MEN1 germline mutation in that patient (1132delG) or with another gene to produce features of MEN2, including pheochromocytoma and thickened corneal nerves. Nevertheless, our current patient had no detected variants detected in the RET protooncogene.

A review of the literature has identified approximately 20 reported cases of PHEO and/or paraganglioma in patients with MEN1 (Table 2). The average reported age is $~ 46$ years old, with the youngest patient identified at the age of 29. Our case represents the oldest MEN1 patient identified with PHEO. Two patients were identified to have bilateral PHEOs and three also died as a result of malignant PHEO. In the majority of cases reported, the size of the PHEO was $>2.5 \mathrm{~cm}$, with the exception of one patient who was reported to have a $1 \mathrm{~cm}$ PHEO (abstract only) (9). The size of our patient's PHEO was also initially identified to be $\geq 2.5 \mathrm{~cm}$. Similar to other familial syndromes, the typical size of PHEO in disease like NF1, MEN2 and VHL can range anywhere from $2.5 \mathrm{~cm}$ to $5.6 \mathrm{~cm}(10,11,12)$. There is no male or female predominance. No clear phenotype--genotype correlation exists for any MEN1 manifestation. Five cases reported hypertension, while our case in addition to two other cases $(13,14)$ had pathologically confirmed PHEO in the absence of symptoms. Screening with 24-h urinary or plasma metanephrines and catecholamines is warranted in adrenal incidentalomas in patients with MEN1, particularly if the adrenal mass suggests PHEO on imaging (vascular, dense and slow contrast washout on $\mathrm{CT}$ ) or is growing $>1 \mathrm{~cm} /$ year.

Radionuclide imaging modalities are critical in the evaluation and management of neuroendocrine tumors. Radiotracers specifically detect and localize neuroendocrine tumors based on tumor receptor availability. In 2016, ${ }^{68} \mathrm{Ga}$-DOTATATE PET/CT was Food and Drug Administration (FDA) approved for the detection of neuroendocrine tumors. There are no reports on functional imaging studies for PHEO in MEN1. However, data on sporadic PHEO suggests that ${ }^{18} \mathrm{~F}-\mathrm{FDOPA}$ PET/CT may have minimally better patient-based and lesion-based detection rates than ${ }^{68} \mathrm{Ga}$-DOTATATE PET/ CT ( $100 \%$ vs $90 \%$ and $94 \%$ vs $81 \%$, respectively) (5). Data from NIH on apparently sporadic PHEOs also demonstrates similar effectiveness between ${ }^{18} \mathrm{~F}$-FDOPA and ${ }^{68} \mathrm{Ga}$-DOTATATE PET/CT (15). There are at least 20 known 


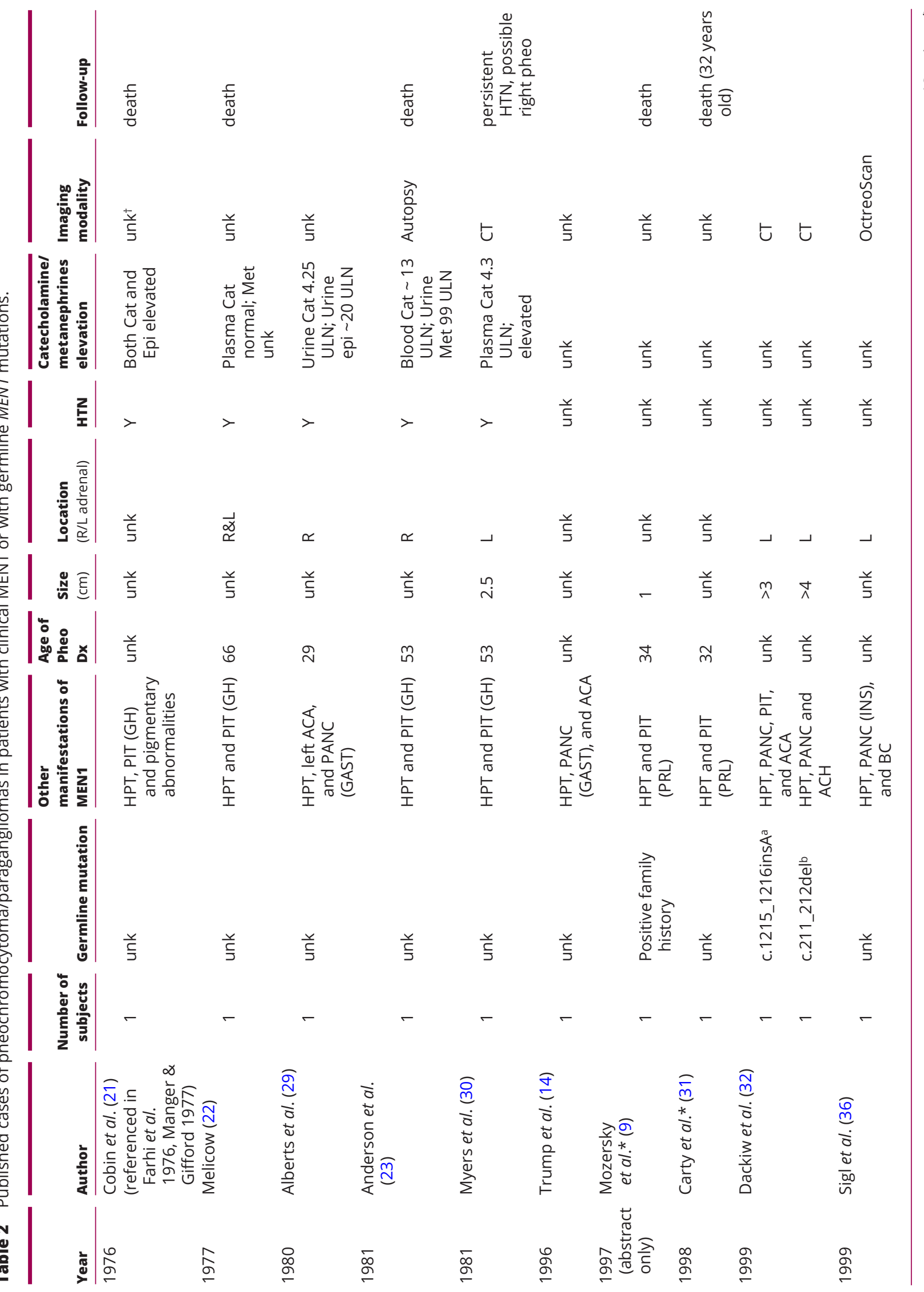


|
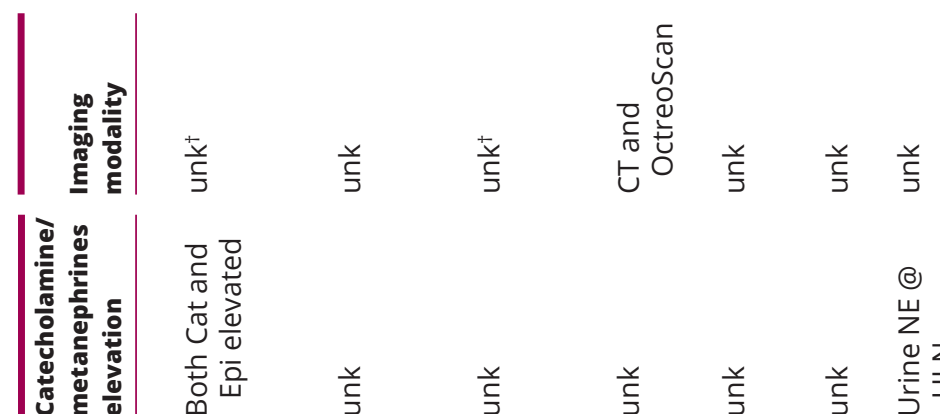

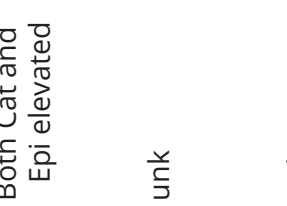

$\mid$

z

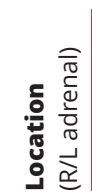

जू है

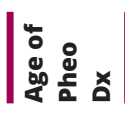

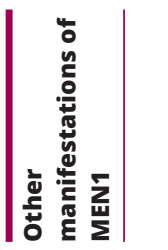

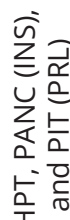

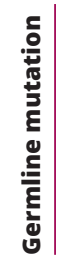

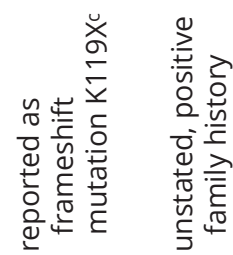

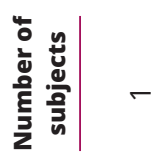

כ

产

旁

盀

产

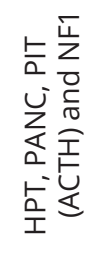

ळ $\quad$ है

妾 站

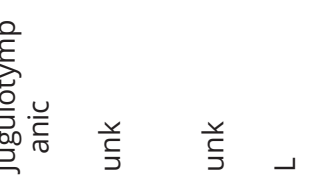

ㅇํ ปे ङ

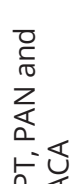

$\stackrel{\longleftarrow}{5}$ $z$

녿

$>\quad \stackrel{\frac{5}{5}}{5}>\quad \frac{y}{5}$

$\simeq$

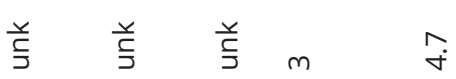

产

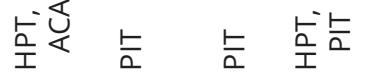

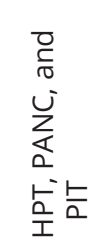

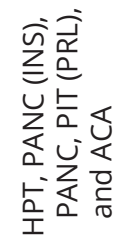

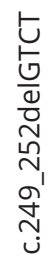

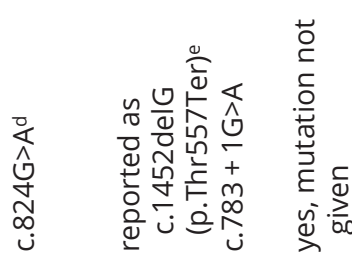

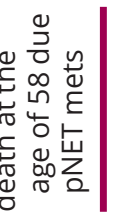

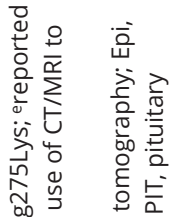

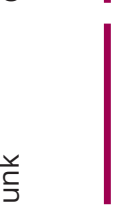

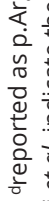

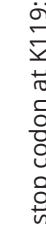

它

产

$>\quad 1$

文

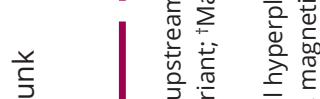

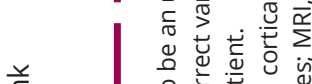

喜

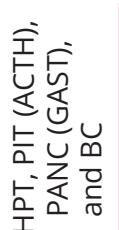

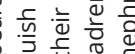

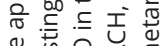

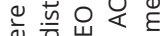

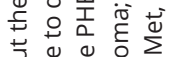

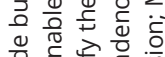

证

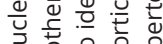

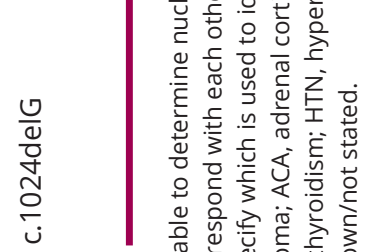

造论 它

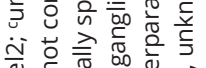

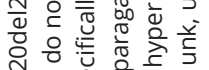

mo

年

要

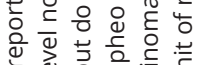

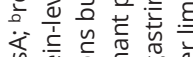

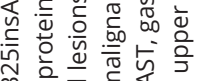

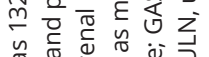

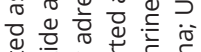

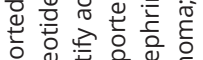

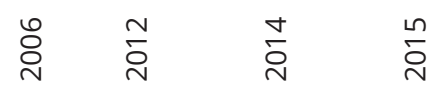

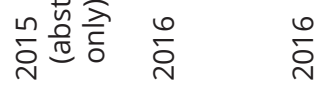

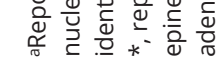


susceptibility genes (not including MEN1) (16) driving the pathogenesis of $\mathrm{PHEO} /$ paraganglioma in hereditary PHEO, which comprises $35-40 \%$ of cases (17). Germline mutations have been associated with improved radiotracer concentrations and is based on molecular clustering. Cluster 1 PHEOs with pseudohypoxic Krebs cycle-related gene, for example, $S D H x$ mutations are best seen on ${ }^{68} \mathrm{Ga}$-DOTATATE PET/CT, while PHEOs with pseudohypoxia VHL/EPAS1-related signaling mutations are best seen on 18F-FDOPA PET/CT (16). Kinase signaling related PHEO (cluster 2) which includes RET, NF1 and MAX mutations are also best imaged using ${ }^{18 F-F D O P A ~ P E T / C T ~}(18,19)$. Our patient had elevations in normetanephrine, metanephrines and epinephrine, thus not clearly identifying into one biochemical phenotype. It is not known which imaging modality is best for MEN1associated PHEO, given the rarity of these tumors in MEN1 patients. In our patient, only ${ }^{18}$ F-FDOPA PET/CT accurately detected and lateralized the PHEO. It should be noted that $18 \mathrm{~F}$-FDOPA PET/CT is not readily available nor routinely used in MEN1. However, this imaging modality may be a helpful tool to distinguish PHEO in an MEN1 patient with bilateral adrenal nodules. The specificity or sensitivity of ${ }^{68} \mathrm{Ga}$-DOTATATE PET/CT for PHEO in MEN1 in unknown.

A recently described rare syndrome of pituitary adenomas plus $\mathrm{PHEO} /$ paraganglioma (3PAs) has been associated with mutations in $S D H B$ (cluster 1) and RET (cluster 2), which are two of the most prevalent germline mutations in patients with PHEO/paraganglioma (20). A report of a 54-year-old male patient with acromegaly and incidentally identified bilateral PHEO had a heterozygous germline variant of uncertain significance in MEN1 (c.1618C > T; p.Pro540Ser) (20). Additional cases with clinical history suggesting MEN1 (prior to the MEN1 gene discovery in 1997) include PHEO combined most commonly with hyperparathyroidism, gastrinoma and/or acromegaly (Table 2) $(21,22,23,24)$.

Loss of heterozygosity (LOH) at the MEN1 locus has been described in two previous PHEO cases in MEN1 patients (25). We also confirmed LOH at the MEN1 locus in the PHEO tumor of our patient, suggesting that MEN1 is implicated in the tumorigenesis of PHEO. Little is known about the role of menin in the pathogenesis of PHEO. Interestingly, 7\% of Men $1^{+/-}$mice develop bilateral pheochromocytomas, which are equally distributed between sexes (26). Further work is needed to identify epigenetic or modifying factors that may explain the rare occurrence of these tumors in MEN1 patients.
In this study, we report a rare case of PHEO in a patient with a germline mutation in MEN1. 18F-FDOPA PET/ CT was the most sensitive functional imaging modality when compared to ${ }^{123} \mathrm{I}-\mathrm{mIBG}$ and ${ }^{18} \mathrm{~F}-\mathrm{FDG}$ PET/CT. Rarely, MEN1 patients may develop functional and/or enlarging adrenal nodules $>2 \mathrm{~cm}$ which require biochemical evaluation, even in the absence of symptomatology. Due to the frequency of bilateral adrenal nodules in MEN1, functional imaging for PHEO may be essential.

\section{Declaration of interest}

The authors declare that there is no conflict of interest that could be perceived as prejudicing the impartiality of the research reported.

\section{Funding}

A A T, JW, M L, A M, S K A, C C, R M, W F S, L S W and J E B are supported by funding from the Intramural Research Program of the National Institute of Diabetes and Digestive and Kidney Disease (NIDDK). J D R, N N and D P are supported by the Intramural Program of the National Cancer Institute (NCl). C C is supported by Intramural Program of Clinical Center PET Department (CC/PET). A J and K P are supported by Eunice Kennedy Shriver National Institute of Child Health Development (NICHD).

\section{Patient consent}

Written informed consent has been obtained from the patient.

\section{Author contribution statement}

A A Tepede and J E Blau contributed to the conception, writing and editing of the manuscript. K Pacak, J E Blau, W F Simonds and L S Weinstein participated in the endocrine attendings and were the primary providers in the clinical and research care for the patient and involved in editing and revising the manuscript. N Nilubol performed the laparoscopic retroperitoneal left adrenal adenoma resection and was involved in editing and revising the manuscript. C Millo was the radiologist involved in the interpretation and selection of anatomic and nuclear imaging for publication and was involved in editing and revising the manuscript. J Welch and S K Agarwal performed DNA sequencing on the tumor and were involved in editing and revising the manuscript. C Cochran coordinated the clinical care of the patient. A Jha, D Patel, A Mandl and M Lee were involved in editing and revising the manuscript.

\section{References}

1 Thakker RV. Multiple endocrine neoplasia type 1 (MEN1). Best Practice and Research: Clinical Endocrinology and Metabolism 201024 355-370. (https://doi.org/10.1016/j.beem.2010.07.003)

2 Gatta-Cherifi B, Chabre O, Murat A, Niccoli P, Cardot-Bauters C, Rohmer V, Young J, Delemer B, Du Boullay H, Verger MF, et al. Adrenal involvement in MEN1. Analysis of 715 cases from the Groupe d'étude des Tumeurs Endocrines database. European Journal of Endocrinology 2012166 269-279. (https://doi.org/10.1530/EJE-11-0679)

3 Thakker RV, Newey PJ, Walls GV, Bilezikian J, Dralle H, Ebeling PR, Melmed S, Sakurai A, Tonelli F, Brandi ML, et al. Clinical practice 
guidelines for multiple endocrine neoplasia Type 1 (MEN1). Journal of Clinical Endocrinology and Metabolism 201297 2990-3011. (https:// doi.org/10.1210/jc.2012-1230)

4 Taïeb D, Jha A, Guerin C, Pang Y, Adams KT, Chen CC, Romanet P, Roche P, Essamet W, Ling A, et al. 18F-FDOPA PET/CT imaging of MAX-related pheochromocytoma. Journal of Clinical Endocrinology and Metabolism 2018103 1574-1582. (https://doi.org/10.1210/ jc.2017-02324)

5 Archier A, Varoquaux A, Garrigue P, Montava M, Guerin C, Gabriel S, Beschmout E, Morange I, Fakhry N, Castinetti F, et al. Prospective comparison of 68Ga-DOTATATE and 18F-FDOPA PET/CT in patients with various pheochromocytomas and paragangliomas with emphasis on sporadic cases. European Journal of Nuclear Medicine and Molecular Imaging 201643 1248-1257. (https://doi.org/10.1007/ s00259-015-3268-2)

6 Képénékian L, Mognetti T, Lifante JC, Giraudet AL, Houzard C, Pinson S, Borson-Chazot F \& Combemale P. Interest of systematic screening of pheochromocytoma in patients with neurofibromatosis type 1. European Journal of Endocrinology 2016175 335-344. (https:// doi.org/10.1530/EJE-16-0233)

7 Luster M, Karges W, Zeich K, Pauls S, Verburg FA, Dralle H, Glatting G, Buck AK, Solbach C, Neumaier B, et al. Clinical value of 18F-fluorodihydroxyphenylalanine positron emission tomography/ computed tomography (18F-DOPA PET/CT) for detecting pheochromocytoma. European Journal of Nuclear Medicine and Molecular Imaging 201037 484-493. (https://doi.org/10.1007/s00259-009-1294-7)

8 El-Maouche D, Welch J, Agarwal SK, Weinstein LS, Simonds WF \& Marx SJ. A patient with MEN1 typical features and MEN2-like features. International Journal of Endocrine Oncology 20163 89-95. (https://doi.org/10.2217/ije-2015-0008)

9 Mozersky RP, Girdhar R, Palushock S, Patel N, Nolan S \& Bahl VK. Malignant nonfunctioning pheochromocytoma occurring in a mixed multiple endocrine neoplasia syndrome. Endocrine Practice 19973 236-239. (https://doi.org/10.4158/EP.3.4.236)

10 Jalbani IK, Nazim SM \& Abbas F. Pheochromocytoma associated with von Hippel-Lindau disease in a Pakistani family. Urology Annals 2015 7 120-123. (https://doi.org/10.4103/0974-7796.148660)

11 Shinall MC \& Solórzano CC. Pheochromocytoma in neurofibromatosis Type 1: when should it be suspected? Endocrine Practice 201420 792-796. (https://doi.org/10.4158/EP13417.OR)

12 Thosani S, Ayala-Ramirez M, Palmer L, Hu MI, Rich T, Gagel RF, Cote G, Waguespack SG, Habra MA \& Jimenez C. The characterization of pheochromocytoma and its impact on overall survival in multiple endocrine neoplasia type 2. Journal of Clinical Endocrinology and Metabolism 201398 E1813-E1819. (https://doi. org/10.1210/jc.2013-1653)

13 Motazedi B, Rahmani M, Welch JM \& Motazedi A. First report of concomitant pheochromocytoma and duodenal neuroendocrine tumour in a sporadic multiple endocrine neoplasia type 1. BMJ Case Reports 20182018 bcr-2017-222947. (https://doi.org/10.1136/bcr2017-222947)

14 Trump D, Farren B, Wooding C, Pang JT, Besser GM, Buchanan KD, Edwards CR, Heath DA, Jackson CE, Jansen S, et al. Clinical studies of multiple endocrine neoplasia type 1 (MEN1). QJM: Monthly Journal of the Association of Physicians 199689 653-669. (https://doi. org/10.1093/qjmed/89.9.653)

15 Abhishek Jha AL, Millo C, Chen C, Gonzales M, Patel M, Tena I, Mamilla D, Knue M, O'Sullivan Coyne G, Chen A, et al. Diagnostic performance of PET/CT utilizing 68Ga-DOTATATE, 18F-FDG, 18F-DOPA, and 18F-FDA, and anatomic imaging in the detection of sporadic primary pheochromocytoma - a comparative prospective study. Journal of Nuclear Medicine 201960439.

16 Taieb D, Jha A, Treglia G \& Pacak K. Molecular imaging and radionuclide therapy of paraganglioma and pheochromocytoma. Endocrine-Related Cancer 201926 R627-R652. (https://doi.org/10.1530/ erc-19-0165)
17 Moraitis AG, Martucci VL \& Pacak K. Genetics, diagnosis, and management of medullary thyroid carcinoma and pheochromocytoma/paraganglioma. Endocrine Practice 201420 176-187. (https://doi.org/10.4158/EP13268.RA)

18 Nölting S, Ullrich M, Pietzsch J, Ziegler CG, Eisenhofer G, Grossman A \& Pacak K. Current management of pheochromocytoma/paraganglioma: a guide for the practicing clinician in the era of precision medicine. Cancers 2019111505. (https://doi.org/10.3390/cancers11101505)

19 Taïeb D, Hicks RJ, Hindié E, Guillet BA, Avram A, Ghedini P, Timmers HJ, Scott AT, Elojeimy S, Rubello D, et al. European Association of Nuclear Medicine Practice Guideline/Society of Nuclear Medicine and Molecular Imaging Procedure Standard 2019 for radionuclide imaging of phaeochromocytoma and paraganglioma. European Journal of Nuclear Medicine and Molecular Imaging 201946 2112-2137. (https://doi.org/10.1007/s00259-01904398-1)

20 Guerrero-Pérez F, Fajardo C, Torres Vela E, Giménez-Palop O, Lisbona Gil A, Martín T, González N, Díez JJ, Iglesias P, Robledo M, et al. 3P association (3PAs): pituitary adenoma and pheochromocytoma/ paraganglioma. A heterogeneous clinical syndrome associated with different gene mutations. European Journal of Internal Medicine 2019 69 14-19. (https://doi.org/10.1016/j.ejim.2019.08.005)

21 Manger W \& Gifford R. Pheochromocytoma, 1st ed. New York, NY: Springer-Verlag, 1977.

22 Melicow MM. One hundred cases of pheochromocytoma (107 tumors) at the Columbia-Presbyterian Medical Center, 1926-1976. A clinicopathological analysis. Cancer 197740 1987-2004. (https://doi.org/10.1002/1097-0142(197711)40:5<1987::aidcncr2820400502>3.0.co;2-r)

23 Anderson RJ, Lufkin EG, Sizemore GW, Carney JA, Sheps SG \& Silliman YE. Acromegaly and pituitary adenoma WITH phaeochromocytoma: a variant of multiple endocrine neoplasia. Clinical Endocrinology 198114 605-612. (https://doi. $\operatorname{org} / 10.1111 /$ j.1365-2265.1981.tb02971.x)

24 Farhi F, Dikman SH, Lawson W, Cobin RH \& Zak FG. Paragangliomatosis associated with multiple endocrine adenomas. Archives of Pathology and Laboratory Medicine 1976100 495-498.

25 Dénes J, Swords F, Rattenberry E, Stals K, Owens M, Cranston T, Xekouki P, Moran L, Kumar A, Wassif C, et al. Heterogeneous genetic background of the association of pheochromocytoma/paraganglioma and pituitary adenoma: results from a large patient cohort. Journal of Clinical Endocrinology and Metabolism 2015100 E531-E541. (https:// doi.org/10.1210/jc.2014-3399)

26 Crabtree JS, Scacheri PC, Ward JM, Garrett-Beal L, Emmert-Buck MR, Edgemon KA, Lorang D, Libutti SK, Chandrasekharappa SC, Marx SJ, et al. A mouse model of multiple endocrine neoplasia, type 1, develops multiple endocrine tumors. PNAS 200198 1118-1123. (https://doi.org/10.1073/pnas.98.3.1118)

27 Manickam P, Guru SC, Debelenko LV, Agarwal SK, Olufemi SE, Weisemann JM, Boguski MS, Crabtree JS, Wang Y, Roe BA, et al. Eighteen new polymorphic markers in the multiple endocrine neoplasia type 1 (MEN1) region. Human Genetics 1997101 102-108. (https://doi.org/10.1007/s004390050595)

28 Debelenko LV, Emmert-Buck MR, Manickam P, Kester M, Guru SC, DiFranco EM, Olufemi SE, Agarwal S, Lubensky IA, Zhuang Z, et al. Haplotype analysis defines a minimal interval for the multiple endocrine neoplasia type 1 (MEN1). Cancer Research 199757 1039-1042.

29 Alberts WM, McMeekin JO \& George JM. Mixed multiple endocrine neoplasia syndromes. JAMA 1980244 1236-1237. (https://doi. org/10.1001/jama.1980.03310110046029)

30 Myers JH \& Eversman JJ. Acromegaly, hyperparathyroidism, and pheochromocytoma in the same patient: a multiple endocrine disorder. Archives of Internal Medicine 1981141 1521-1522. (https:// doi.org/10.1001/archinte.1981.00340120129027) 
31 Carty SE, Helm AK, Amico JA, Clarke MR, Foley TP, Watson CG \& Mulvihill JJ. The variable penetrance and spectrum of manifestations of multiple endocrine neoplasia type 1. Surgery $1998 \mathbf{1 2 4} 1106-1113$; discussion 1113. (https://doi.org/10.1067/msy.1998.93107)

32 Dackiw APB, Cote GJ, Fleming JB, Schultz PN, Stanford P, Vassilopoulou-Sellin R, Evans DB, Gagel RF \& Lee JE. Screening for MEN1 mutations in patients with atypical endocrine neoplasia. Surgery 1999126 1097-1103; discussion 1103. (https://doi. org/10.1067/msy.2099.101376)

33 Langer P, Cupisti K, Bartsch DK, Nies C, Goretzki PE, Rothmund M \& Röher HD. Adrenal involvement in multiple endocrine neoplasia Type 1. World Journal of Surgery 200226 891-896. (https://doi. org/10.1007/s00268-002-6492-4)

34 Jäger AC, Friis-Hansen L, Hansen TV, Eskildsen PC, Sølling K, Knigge U, Hansen CP, Andersen PH, Brixen K, Feldt-Rasmussen U, et al. Characteristics of the Danish families with multiple endocrine neoplasia type 1. Molecular and Cellular Endocrinology 2006249 $123-132$
35 Jamilloux Y, Favier J, Pertuit M, Delage-Corre M, Lopez S, Teissier MP, Mathonnet M, Galinat S, Barlier A \& Archambeaud F. A MEN1 syndrome with a paraganglioma. European Journal of Human Genetics 201422 283-285. (https://doi.org/10.1038/ ejhg.2013.128)

36 Sigl E, Behmel A, Erdel T, Wirnsberger G, Weinhäusel A, Kaserer K, Niederle B \& Pfragner R. Cytogenetic and CGH studies of four neuroendocrine tumors and tumor-derived cell lines of a patient with multiple endocrine neoplasia type 1. International Journal of Oncology 199915 41-51. (https://doi.org/10.3892/ijo.15.1.41)

37 Okada R, Shimura T, Tsukida S, Ando J, Kofunato Y, Momma T, Yashima R, Koyama Y, Suzuki S \& Takenoshita S. Concomitant existence of pheochromocytoma in a patient with multiple endocrine neoplasia type 1. Surgical Case Reports 20162 84. (https:// doi.org/10.1186/s40792-016-0214-x)

38 Hasan F. Pheochromocytoma in Multiple Endocrine Neoplasia Type-1: A Case Report and Literature Review. San Diego, California: Endocrine Society, 2015.

Received in final form 17 January 2020

Accepted 11 February 2020 